\title{
Replacement of an aortic valve cusp after neonatal endocarditis
}

\author{
R M R Tulloh, E D Silove, L D Abrams
}

\begin{abstract}
Septic arthritis developed in a neonate after an infection of her hand. Despite medical and surgical treatment endocarditis of her aortic valve developed and the resultant regurgitation required emergency surgery. At operation a new valve cusp was fashioned from preserved calf pericardium. Nine years later she was well and had full exercise tolerance with minimal aortic regurgitation.
\end{abstract}

Bacterial endocarditis is an uncommon condition in childhood. Despite antibiotics the mortality remains high $(8 \% \text { to } 40 \%)^{1-3}$ and the risk of death is higher in those who need emergency surgery. ${ }^{4}$

\section{Case report}

A female infant was born on 29 September 1980 after a normal pregnancy. An emergency caesarean section was performed for fetal distress and the $3.9 \mathrm{~kg}$ baby was delivered uneventfully.

When she was 2 weeks old a tender septic spot was noticed on the palm of her left hand and a temperature of $39^{\circ} \mathrm{C}$ was recorded. Three days later the right hand was swollen and the left thigh became hot and tender. On 26 October she was admitted to her local hospital; an abscess was drained from the left hip joint and treatment with intravenous ampicillin and cloxacillin was started. Staphylococcus aureus was cultured from the pus. By 16 November swelling and tenderness of the left thigh developed and osteomyelitis was diagnosed. After additional treatment with intravenous fusidic acid this seemed to settle and she was discharged home on 26 November.

She was again admitted on 9 December

The Heart Unit, The Children's Hospital, Birmingham R M R Tulloh E D Silove L D Abrams

Correspondence to Dr R M R Tulloh, The Heart Unit, The Children's Hospital, Ladywood Middleway, Birmingham B16 8ET. was hyperdynamic and there were systolic and diastolic murmurs that were loudest in the aortic area. The infection in the hip joint and was transferred two days later to the Children's Hospital, Birmingham for further investigation. On admission she was very ill seemed to be quiescent. Echocardiography showed that the non-coronary cusp of the aortic valve was flipping in and out of the left ventricle. The diameter of the aortic root was $1.2 \mathrm{~cm}$ on $\mathrm{M}$ mode echocardiography. Cardiac catheterisation and angiography showed severe aortic regurgitation through the noncoronary cusp.

That day the aortic valve was explored on cardiopulmonary bypass under hypothermic arrest. The non-coronary cusp of the aortic valve was found to be grossly abnormal. It was rolled up into a small bead and floating freely, attached only by a string to one commissure. The valve cusp was excised and replaced with a piece of preserved calf pericardium (Ionescu-Shiley prosthesis) tailored into the shape of a cusp to extend beyond the centre of the aortic lumen and overlap the other two cusps. Each commissure was extended a little higher than the normal cusps to give proper depth to the oversized prosthetic cusp. During the operation the heart function was seen to improve.

Postoperatively the cardiac failure resolved and she continued to be treated with digoxin and frusemide. The presumed infection was treated with flucloxacillin and fusidic acid. Satisfactory plasma concentrations of the antibiotics were achieved. A further complication was the development of a septic aneurysm of the right common iliac artery, which was repaired surgically one week later. The left hip was also found to be unstable and dislocated. It was splinted in a frog plaster for 4 months and valgus osteotomy was performed in 1986.

At the most recent follow up in August 1989 she was almost nine years old taking part in ballet and with a full exercise tolerance. Clinically there was no evidence of cardiac enlargement. A very soft systolic murmur was heard in the aortic area with a barely audible short early diastolic murmur at the left sternal border. Echocardiography showed normal opening of the aortic valve with slight thickening of the non-coronary cusp. The peak Doppler velocity in the ascending aorta was $1.8 \mathrm{~m} / \mathrm{s}$ and there was evidence of slight aortic regurgitation. The left ventricular end diastolic diameter was $4.5 \mathrm{~cm}$ (slightly greater than the upper limit of normal for a child weighing $21.4 \mathrm{~kg}$ ). The diameter of the aortic root was $1.8 \mathrm{~cm}$. 


\section{Discussion}

This seems to be a unique case of so small a child surviving with a good long term result after reconstructive surgery on the aortic valve after damage by staphylococcal endocarditis. Patients who have infective lesions of the aortic valve often require emergency surgery for life threatening complications. Normally this would be valve replacement. This would have been both undesirable and extremely difficult in such a young child.

Aortic valve repair has been performed previously by extending the cusps with preserved pericardium in adolescents and adults ${ }^{5}$ but we have not found a report of cusp replacement in an infant. In our patient the new cusp was carefully fashioned to allow for growth of the child, with the commissures being extended to give proper depth to the oversized cusp. Such prostheses are likely to calcify and this child may require valve replacement later. The good result was probably the result of growth of the native cusps, which in turn gave support to the pericardial cusp. We do not believe that all three cusps could be so successfully replaced. The aortic valve root has grown along with the child. The course so far is extraordinary and promising.

1 Cleary TG, Kohl S. Anti-infective therapy of infectious endocarditis. Pediatr Clin North Am 1983;30:349-64.

2 Moy RJD, George RH, de Giovanni JV, Silove ED Improving survival in bacterial endocarditis. Arch Dis Child 1986;61:394-9.

3 Rylance GW, George RH. Antibiotic therapy-approach and duration. In: Meadow R, ed. Recent advances in paediatrics No 7. Edinburgh: Churchill Livingstone,

4 Stanton BF, Baltimore RS, Clemens JD. Changing spectrum of infective endocarditis in children. Am J Dis Child 1984;138:720-5.

5 Al-Fagih MR, Al-Kasab SM, Ashmeg A. Aortic valve repair using bovine pericardium for cusp extension. $J$ Thorac Cardiovasc Surg 1988;96:760-4. 